\title{
Panorama da inclusão de alunos com deficiência no ensino superior em Juiz de Fora, MG
}

Emerson Rodrigues Duarte* Maria Elisa Caputo Ferreira**

\begin{abstract}
Resumo
Este trabalho procurou colaborar para que o atual paradigma educacional da inclusão de pessoas com deficiência seja rompido possibilitando o estabelecimento de novos processos educacionais. Justifica-se pela necessidade contemporânea de estabelecer processos e metodologias, em políticas educacionais, que contemplem o Ensino Superior atento à diversidade humana. Para tanto, buscou-se recorrer aos conhecimentos já produzidos a respeito do tema inclusão, especificamente, nesta etapa de ensino, com base nos autores, tais como Mansini e Bazon (2006), Delpino (2004), Moreira (2005), Gomes e Lima (2006), Perini (2006), Chahin (2006), Pellegrin (2006), Ferreira (2006), Pacheco e Costas (2006), Rodrigues (2007), Pereira (2007). O objetivo deste trabalho foi realizar um levantamento dos alunos auto declarados com deficiência em processo de inclusão nas Instituições de Ensino Superior de Juiz de Fora. Metodologicamente, esta pesquisa foi realizada através de um Survey, em que foi possível levantar quem são os alunos com deficiência matriculados nas Instituições de Ensino Superior, na cidade de Juiz de Fora. O instrumento utilizado foi entrevista semiestruturada aplicada aos coordenadores de cursos de dez Instituições de Ensino Superior (IESs) privada e de uma IES pública. Conclui-se que a inclusão nos cursos superiores em Juiz de Fora vem acontecendo. Atualmente, são 45 alunos com deficiência em processo de inclusão, sendo 82,2\% na rede privada e $17,8 \%$ na rede pública. Em sua maioria alunos com deficiência visual $(40 \%)$, do sexo masculino $(62,2 \%)$. Estudam no período noturno $(84,4 \%)$ e há maior procura pelos cursos da área de Humanidades $(71,1 \%)$.
\end{abstract}

Palavras-chave: Ensino Superior. Inclusão. Pessoas com deficiência.

\section{Overview of inclusion of students with disabilites in higer education of Juiz de Fora, MG}

\section{Abstract}

This work has sought to help break this educational paradigm, focusing mainly on higher education. It can be justified by the current need to establish processes and methodologies in educational policies which deal with higher education which privileges human diversity. In order to do so, knowledge already produced

\footnotetext{
* Professor Rede Municipal de Ensino de Juiz de Fora e do Curso de bacharelado de Educação Física da Faculdade Estácio de Sá. Juiz de Fora, Minas Gerais, Brasil.

** Professora Doutora da Faculdade de Educação Física da Universidade Federal de Juiz de Fora (UFJF). Juiz de Fora, Minas Gerais, Brasil.
} 
on the theme of inclusion - specifically concerning higher education- was sought in authors such as Mansini and Bazon (2006), Delpino (2004), Moreira (2005), Gomes and Lima (2006), Perini (2006), Chahin (2006), Pellegrin (2006), Ferreira (2006), Rodrigues (2007), and Pereira (2007). The aim of this dissertation was to do a survey of the students with disabilities in process of inclusion in the higher education institutions of Juiz de Fora. Methodologically, this research was a survey carried out to know how many students with disabilities are enrolled in the higher education institutions of Juiz de Fora. The tool used was a semi-structured interview applied to the course coordinators of the private Higher Education Institutions (HEI) and of one public HEl. The conclusion is that inclusion is a reality in the higher education institutions of Juiz de Fora. Currently, 45 students with disabilities are in the process of inclusion, 37 of whom are in private institutions and 8 in the public ones. Most of them are visually impaired males. They attend evening courses, mostly in the Humanities.

Keywords: Higher education. Inclusion. People with disabilities.

\section{Introdução}

Este artigo tem como tema principal a inclusão de pessoas com deficiência no ensino superior. Nesse momento histórico brasileiro, tal temática merece destaque vista ás políticas implementadas pelo Governo Federal de acesso ao Ensino Superior, como o ProUni, o Incluir e o Reuni com o objetivo de ampliar o nível de escolarização da população.

No mundo contemporâneo, a inclusão do aluno com deficiência representa desafio, desde a modalidade de Educação Infantil até o Ensino Superior, em instituições públicas e privadas. No Brasil, as estatísticas oficiais, estudos e pesquisas, elucidam principalmente da condição desse alunado em processo de inclusão na educação básica subsidiados pela Declarações de Educação para Todos (1990) e de Salamanca (1994).

Todavia, pouco se tem documentado sobre a inclusão de pessoas com deficiência no ensino superior indicando uma carência de reflexões, estudos e estatísticas dificultando, assim, a formulação de políticas públicas que contemplem ações que avancem para uma educação inclusiva também no ensino superior.

Entre estes poucos, podemos citar, atualmente, estudiosos como Delpino, (2004); Moreira,(2005); Gomes e Lima (2006); Manzini e Bazon, (2006); Perini, (2006); Chahin, (2006); Pellegrin, (2006); Ferreira (2007); Rodrigues, (2007); Pereira, (2007) que se dedicaram a estudar este paradigma educacional da sociedade pós-moderna apontado valores, processos, caminhos e dificuldades a serem considerados a respeito das possibilidade de acesso e permanência de pessoas com deficiência no ensino superior. 
Especificamente em Juiz de Fora, MG nem na única Universidade Federal da cidade (Universidade Federal de Juiz de Fora), nem nas faculdades privadas foi possível encontrar dados referentes ao número de pessoas com deficiência em seus diversos cursos de graduação.

Por esta lacuna de dados locais, contamos apenas com valores nacionais que apontam para o crescimento do número de matricula de alunos com deficiência no ensino superior de uma forma geral. Segundo o Censo da Educação Superior MEC/INEP 2005, havia, neste ano, 11.999 matrículas de alunos com deficiência no ensino superior sendo deste total 8.190 nas Instituições de Ensino Superior privadas e 3.809 nas Instituições Federais de Ensino Superior (IFES).

É neste sentido que este estudo se justifica, visto que há uma necessidade contemporânea de estabelecer processos e metodologias em políticas educacionais, que considerem sobremaneira a diversidade humana e contemplem o Ensino Superior. Assim, na cidade de Juiz de Fora, há uma barreira para o estabelecimento de tais políticas educacionais, visto que não foram encontrados dados epidemiológicos que abranjam a inclusão de pessoas com deficiência no Ensino Superior. Estes dados tornam-se, portanto, importantes e necessários para o desenvolvimento de estratégias e ações em política pública educacionais. Neste sentido, apresenta-se uma proposta pioneira no intuito de levantar informações relevantes sobre a inclusão de alunos com deficiência nas instituições de ensino superior de Juiz de Fora.

Portanto, adotamos como objetivo realizar levantamento dos alunos auto declarados com deficiência em processo de inclusão no ensino superior nas instituições pública e privadas de Juiz de Fora.

\section{A inclusão/exclusão educacional das pessoas com deficiência}

Podemos considerar o conceito de inclusão muito recente se comparado a trajetória secular de exclusão. Referindo-se aos estudos de Mazzotta (1997), Ferreira (2003) Carmo (2008), e Verotti, Calegari (2009) é possível perceber que ao longo dos séculos houve diversas mudanças conceituais sobre a deficiência e sobre o tratamento dispensado pela sociedade às pessoas que apresentavam deficiências físicas, intelectuais ou sensoriais. Para se ter uma idéia, na Antiguidade estas pessoas eram exterminadas, pois se acreditava que eram amaldiçoadas. Somente na Idade Média este comportamento começou a mudar, devido à influência da Igreja Católica, que considerava todos como criaturas de Deus, independente de possuir ou não uma deficiência. No entanto, elas deixaram de ser mortas para serem segregadas e depender da caridade alheia para sua sobrevivência.

Com a intenção de romper este paradigma de segregação e adotar as idéias de normalização, foi criado o conceito de Integração, referente à necessidade de modificar a pessoa com deficiência - e não a sociedade -, de forma que 
esta pudesse assemelhar-se, o máximo possível, aos demais, para ser inserida e integrada no convívio social.

Entretanto, como afirmam Mazzotti (1997), Ferreira (2003) e Verotti, Calegari (2009) normalizar o indivíduo com deficiência passou a não fazer sentido. O conceito de normalidade é muito relativo e subjetivo. Diante disso, chegou-se à conclusão de que a sociedade também teria sua parcela de contribuição ao processo de inserção das pessoas com deficiência. Os sistemas sociais, que durante séculos não contemplaram as necessidades específicas provenientes das diversidade humana, teriam que se transformar de modo a atender a todos. O processo deve ser bi-direcional. Diante destas constatações e das inúmeras mudanças que vemos hoje eclodir na sociedade, surge o movimento da inclusão, que é conseqüência da visão social de um mundo democrático, onde se anseia respeitar direitos e deveres de todos, independente das diferenças de cada um. A limitação de uma pessoa não pode diminuir seus direitos. As pessoas com deficiência são cidadãos e fazem parte da sociedade e esta deve se preparar para lidar com a diversidade humana.

A "escolarização" é fundamental na constituição do indivíduo que vive numa sociedade como a nossa, ainda marcada pela exclusão, fracasso e o abandono em todos os níveis de ensino. De fato, essa falha significa um grave impedimento da apropriação do saber sistematizado, da construção de funções psicológicas mais sofisticadas, de instrumentos de atuação no meio social e de transformação do sujeito e das condições para a construção de novos conhecimentos. (REGO, 2003).

\title{
A inclusão de pessoas com deficiências no Ensino Superior
}

\begin{abstract}
Embora sejamos a favor da luta pela inclusão escolar das pessoas com deficiência, reconhecemos que os sujeitos envolvidos sofrem todos os tipos de descriminação e de imposição de uma sociedade que os elimina sendo falsa a concepção de que caminhamos rumo à igualdade de oportunidades. (PERINI, 2006, p. 111).
\end{abstract}

Assim, pode-se considerar que o fato de estar "dentro" da sala de aula não implica, necessariamente que os alunos com deficiência estejam incluídos nos processos de ensino-aprendizagem, pois, para isso acontecer, eles precisam se mobilizar e, de fato, absorverem os conteúdos escolares. (GOMES; LIMA, 2006).

Não se pode esquecer, ainda, que o desafio da inclusão no ensino superior passa por decisões que extrapolam os muros das Universidades Públicas. É preciso considerar que a universidade pública brasileira não pode ser tomada como a única responsável por este processo, mas como parte integrante da implementação de políticas públicas que garantam apoio financeiro às 
ações e iniciativas neste contexto. Paralelamente a essa situação, essas Instituições Federais de Ensino Superior (IFES) precisam estar cientes da importância de expor às instâncias governamentais as limitações que enfrentam e apontar encaminhamentos que devem ser tomados para que haja a garantia de acesso, ingresso e permanência desses estudantes, pois contam com profissionais das mais diversas áreas do conhecimento, que podem contribuir com ensino, pesquisa e extensão na área das necessidades educacionais especiais. (MOREIRA, 2005). Acreditamos que com a inclusão, não só a pessoa com deficiência é quem sai beneficiada, mas, todos aqueles envolvidos neste processo educacional vislumbrado de uma forma ampliada. A convivência com a diversidade humana favorece a construção de novas relações e experiências tão indispensáveis e fundamentais na formação contemporânea humana e no desenvolvimento dos professores, profissionais e alunos, ampliando para eles a compreensão dos conceitos de justiça e direito. (LIMA, 2007).

\section{Objetivo}

\section{Geral}

Realizar um levantamento dos alunos com deficiência em processo de inclusão no superior em Juiz de Fora, MG.

\section{Metodologia}

\section{Critérios éticos}

Esta pesquisa foi aprovada pelo Comitê de Ética em Pesquisa com Seres Humanos da UFJF. Foi solicitada autorização a todas as Instituições pesquisadas e disponibilizados a todos participantes o Termo de Consentimento Livre e Esclarecido (TCLE). Todas as entrevistas foram gravadas em mídia digital e posteriormente transcritas na sua íntegra. Foi mantido sigilo nominal de todas Instituições e entrevistados. Todo material se encontra arquivado no Laboratório de Estudos sobre o Corpo da Faculdade de Educação Física da UFJF coordenado pela professora Dra Maria Elisa Caputo Ferreira ficando disponível por cinco anos. Após este período será destruído.

\section{Sujeitos}

Nas IES privadas: coordenadores de cursos que contavam à época da pesquisa com aluno auto declarados com deficiência regularmente matriculado e frequente;

Na IES pública: todos os coordenadores dos 45 cursos oferecidos; 


\section{Critérios de inclusão e exclusão}

Nas IES privadas foram entrevistados os coordenadores que informaram possuir em seu curso aluno auto declarado com deficiência regularmente matriculado e frequente no ano de 2009.

UFJF.

Na IES pública todos os coordenadores dos 45 cursos oferecidos pela

\section{Instituições}

Foram pesquisadas 11 Instituições de Ensino Superior de Juiz de Fora, sendo 10 IESs privadas e uma pública (UFJF).

\section{Análise dos dados}

Os dados quali-quantitativos foram retirados das transcrições das entrevistas e posteriormente analisados com auxílio do programa Microsoft Excel for Windows XP.

\section{Resultados}

A partir dos dados recolhidos, foi possível perceber que existem, atualmente, 45 alunos com deficiência matriculados e frequentes em cursos nas IESs públicas e privadas. A rede privada, representada por 10 instituições, responde com 82,2\% (37 alunos) desse total e a rede pública, representada pela UFJF, 17,8\% (8 alunos) como demonstra o gráfico 1 abaixo.

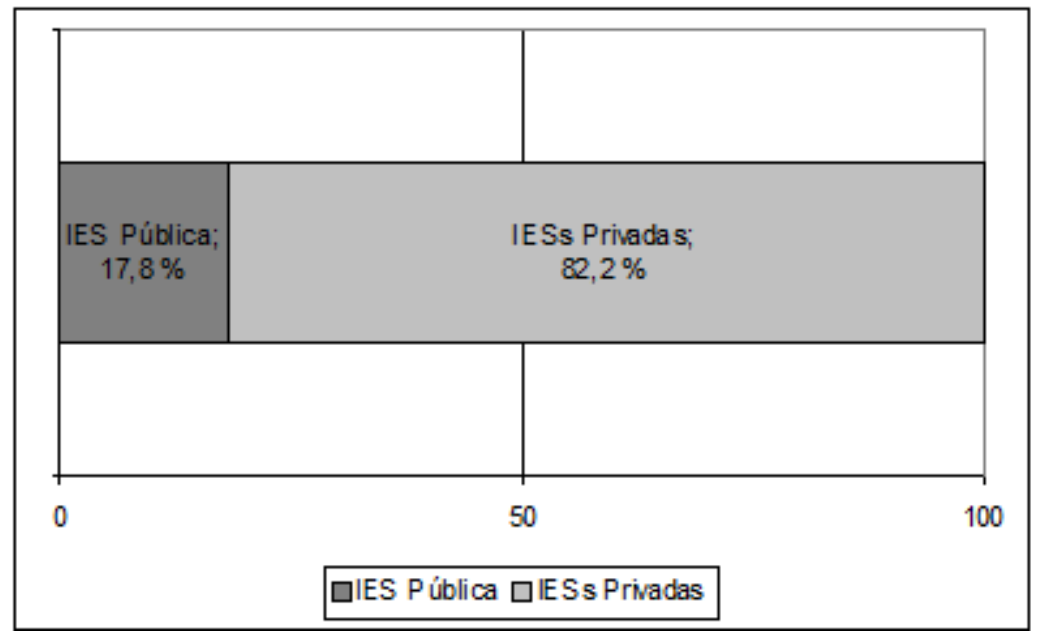

Gráfico 1: Percentual de alunos com deficiência matriculados, por IES pública ou privada.

Fonte: Duarte (2009). 
A maioria das matrículas desses alunos com deficiência, como podemos perceber no gráfico 2, concentra-se na área de Humanidades $(71,1 \%)$, seguida por $17,8 \%$ na área de Saúde e 11,1\% encontra-se na área de Exatas. Na área de Humanidades, os cursos procurados foram: Pedagogia, Direito, Comunicação, Administração, Psicologia, Ciências Contábeis, História e Turismo. Na área da Saúde os cursos frequentados são de Fisioterapia, Educação Física, Medicina e Ciências Biológicas. Na área de Exatas, há alunos matriculados nos cursos de Arquitetura, Ciências da Computação, Design Gráfico, Matemática e Sistemas para Internet.

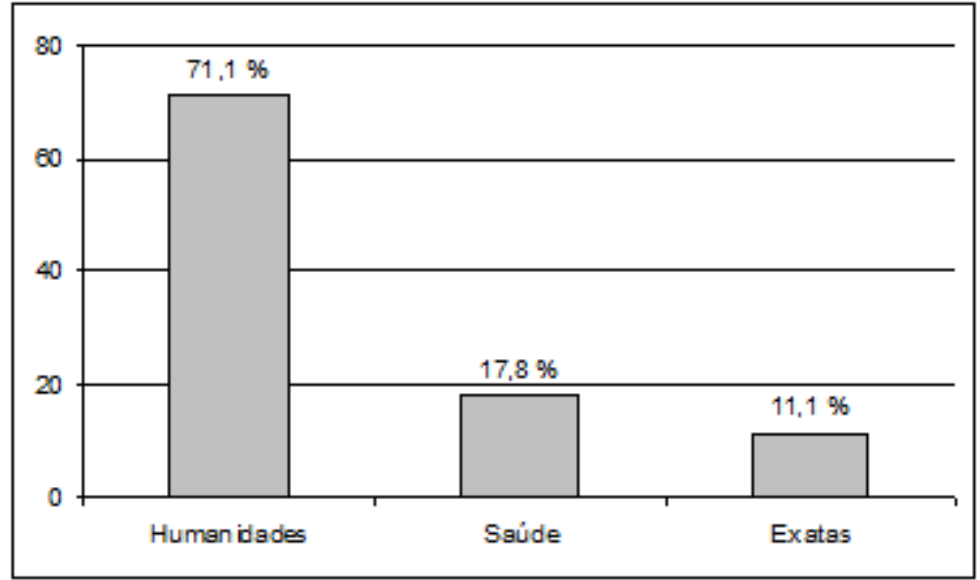

Gráfico 2: Percentual de matriculas de alunos com deficiência por área de conhecimento. Fonte: Duarte (2009).

Constatou-se, também, um número maior de alunos em processo de inclusão nas IESs privadas, como demonstra o gráfico 3, e acredita-se que este fato se deve à maior oferta de cursos noturnos. 


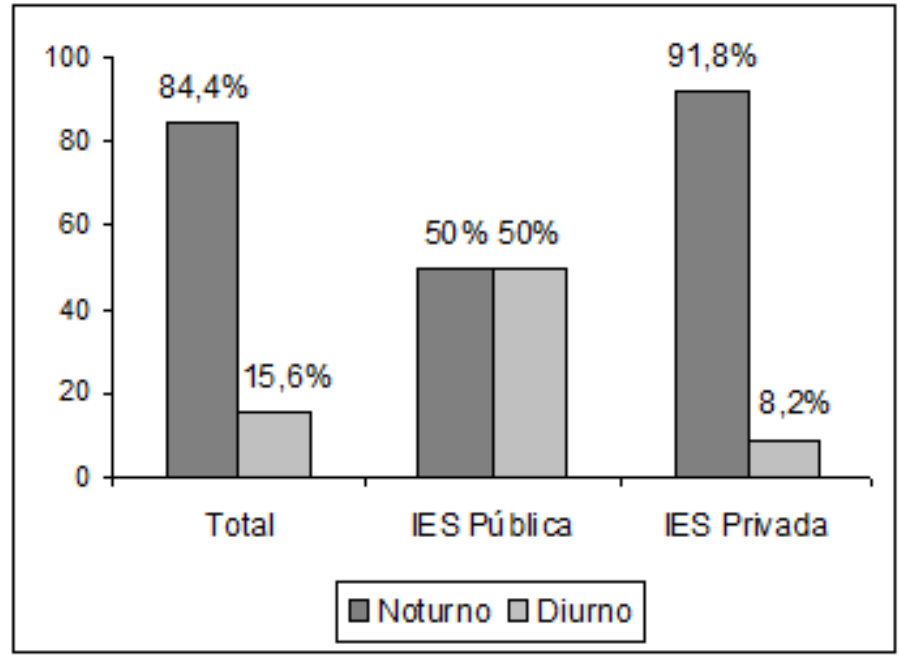

Gráfico 3: Matriculas de alunos com deficiência por turno de estudo. Fonte: Duarte (2009).

Ao se analisarem, na rede privada de Ensino Superior, os alunos com deficiência por gênero, percebeu-se que existem $67,6 \%$ de matrículas de alunos do sexo masculino e $32,4 \%$ do sexo feminino. Na UFJF, os resultados se invertem: há $62,5 \%$ matrículas do sexo feminino e $37,5 \%$ do sexo masculino. No total, prevalece a tendência de maior número de matrículas de alunos do sexo masculino $(62,2 \%)$ e $37,8 \%$ de alunos do sexo feminino de acordo com o gráfico 4. 


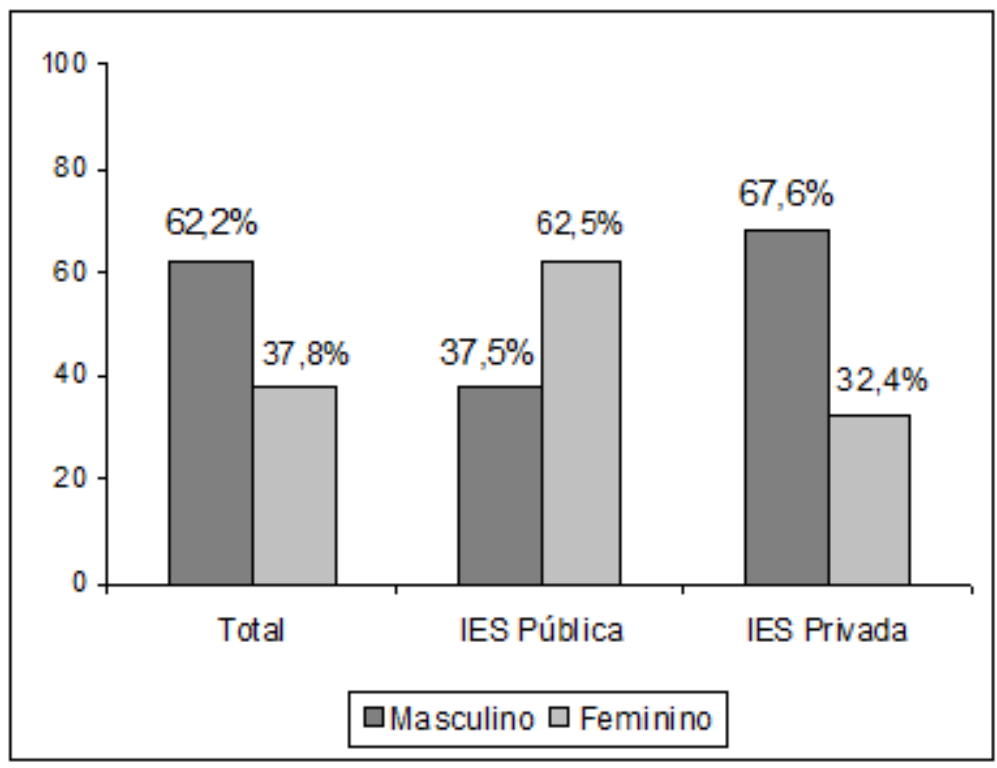

Gráfico 4: Percentual de matriculas de alunos com deficiência por IES e sexo. Fonte: Duarte (2009).

Quando foram analisados os tipos de deficiência, concluiu-se que a deficiência visual apresenta, tanto nas IESs privadas quanto na pública, um maior número de matrículas, correspondente a $40 \%$ do total. A deficiência física corresponde a $33,3 \%$ e a deficiência auditiva, a $26,7 \%$ de acordo com a gráfico 5. 


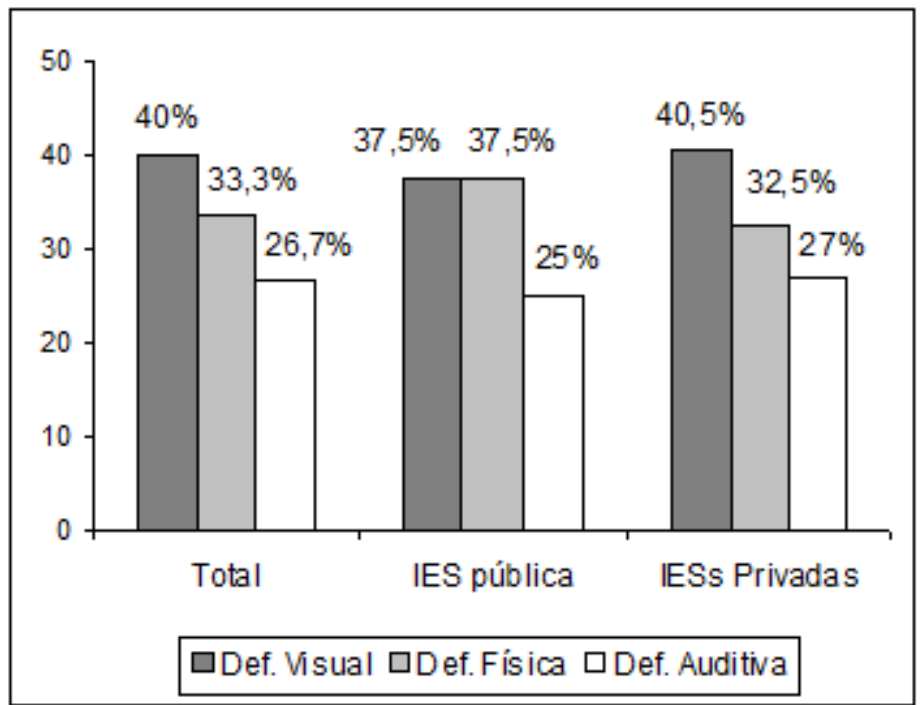

Gráfico 5: Percentual do total de matriculas de alunos com deficiência por deficiência e por IES.

Fonte: Duarte (2009).

\section{Considerações finais}

A realização de estudos que visem ampliar as informações sobre a inclusão de pessoas com deficiência na rede de ensino brasileira, bem como entender o processo de dificuldades, luta e superação desses estudantes até chegar ao Ensino Superior, tem sido importante para auxiliar os profissionais que estão envolvidos na luta pelo direito das pessoas com deficiência e o acesso dos mesmos, em especial, no meio educacional.

Este estudo teve como propósito investigar como vem ocorrendo o processo de inclusão de pessoas com deficiência no Ensino Superior em Juiz de Fora.

À medida que o trabalho foi sendo desenvolvido, descortinavam-se dados referentes à institucionalização de políticas de acesso e permanência de alunos com deficiência, tanto em instituições privadas quanto púbicas de Ensino Superior.

A partir dos resultados obtidos, foi possível chegar ao resultado: a inclusão de pessoas com deficiência no Ensino Superior, em Juiz de Fora, vem se efetivando. Existem, atualmente, 45 alunos com deficiência matriculados e frequentes nas IESs públicas e privadas. A rede privada, representada por 10 
instituições, responde com $82,2 \%$ (37 alunos) desse total e a rede pública, representada pela UFJF, possui $17,8 \%$ (8 alunos). A maioria das matrículas desses alunos com deficiência concentra-se na área de Humanidades $(71,1 \%)$, seguida por 17,8\% na área de Saúde e 11,1\% encontra-se na área de Exatas. $\mathrm{Na}$ área de Humanidades, os cursos procurados foram: Pedagogia, Direito, Comunicação, Administração, Psicologia, Ciências Contábeis, História e Turismo. $\mathrm{Na}$ área da Saúde, os cursos frequentados são de Fisioterapia, Educação Física, Medicina e Ciências Biológicas. Na área de Exatas, há alunos matriculados nos cursos de Arquitetura, Ciências da Computação, Design Gráfico, Matemática e Sistemas para Internet.

Constatou-se, também, um número maior de alunos em processo de inclusão nas IESs privadas e acredita-se que este fato se deve à maior oferta de cursos noturnos.

Ao se analisarem, na rede privada de Ensino Superior, os alunos com deficiência por gênero, percebeu-se que existem $67,6 \%$ de matrículas de alunos do sexo masculino e $32,4 \%$ de alunos do sexo feminino. Na UFJF, os resultados se invertem: há $62,5 \%$ matrículas do sexo feminino e $37,5 \%$ de alunos do sexo masculino. No total, prevalece a tendência de maior número de matrículas de alunos do sexo masculino $(62,2 \%)$ e $37,8 \%$ de alunos do sexo feminino.

Quando foram analisados os tipos de deficiência, concluiu-se que a deficiência visual apresenta, tanto nas IESs privadas quanto na pública, um maior número de matrículas, correspondente a $40 \%$ do total. A deficiência física corresponde a 33,3\% e a deficiência auditiva, a 26,7\%.

A respeito do fato de encontrar-se um número maior de pessoas com deficiência visual em cursos superiores, especificamente em Juiz de Fora, podese destacar a importância da atuação da Associação dos Cegos em Juiz de Fora. Essa instituição, por meio do Programa Aprender a Ser - Projeto de Estudos, oferece a alunos cegos e a todas as IESs que solicitem, poio psicopedagógico específico. Atualmente, o Programa é coordenado por uma pedagoga e conta com 51 voluntários entre professores e estudantes universitários, que leem e auxiliam no entendimento dos conteúdos das disciplinas. Também oferece apoio metodológico através do laboratório de impressão em braile para transcrição de todo material didático utilizado, tais como textos e livros, em impressora própria. Esse Programa é citado nas entrevistas com os coordenadores de cursos como essencial para o sucesso da inclusão de alunos cegos nas IESs pesquisadas. Desta forma, pode-se afirmar sobre a importância da atuação de Associações de/para pessoas com deficiência - na medida do despreparo e na falta de experiência dos gestores municipais, na efetivação de políticas públicas já instituídas e consolidadas mas ainda não reconhecida por esses agentes - na construção, disponibilização e divulgação de tecnologias assistivas para inclusão da pessoa com deficiência. 
Importa ressaltar que não foi encontrado nenhum aluno com deficiência intelectual em processo de inclusão nas instituições pesquisadas.

Sobre as características das ações implementadas a favor do processo de inclusão de pessoas com deficiência nas redes pública e privada de Ensino Superior, foi possível verificar, nas IESs privadas, a existência de núcleos de apoio psicopedagógico, que atuam de forma conjunta com os professores no suporte metodológico, material e humano ao processo de inclusão dos alunos, favorecendo ainda mais a ideia de educação inclusiva enquanto processo e direito.

Foi possível perceber, em relação à UFJF, uma proposta futura de ensino que privilegie a diversidade humana, reconhecendo os diferentes processos de formação de acordo com os interesses dos alunos em que a pessoa com deficiência possa ter oportunidade de sucesso em sua formação superior. Ainda em fase de implantação, reconheceu-se o Programa Incluir como fundamental para ampliar o acesso e a permanência das pessoas com deficiência no ensino público gratuito.

Esse Programa tem como meta apoiar, orientar e acompanhar os alunos que necessitem de atendimento especial, contribuindo para a construção de uma sociedade inclusiva que conviva com a diferença e respeite a diversidade humana.

Espera-se que, por meio do Programa Incluir, estabeleça-se uma relação dialética entre alunos (TODOS), professores, funcionários e gestores para a discussão e elaboração de estudos a fim de que o processo de inclusão e a efetivação de políticas afirmativas sejam cercados de atitudes e métodos adequados para a suas implementações.

Sobre o processo de escolarização da pessoa com deficiência no Brasil, cabe aqui não perder de vista a disparidade entre o discurso político de educação para TODOS e o caráter assistencial e filantrópico que veio ancorando a educação dessas pessoas por um longo período. Mesmo hoje, sob a égide da bandeira inclusiva, são muitos os entraves enfrentados, sobretudo pelos estudantes com deficiência e suas famílias, para garantir dignidade e qualidade à sua educação.

Apesar dos últimos dados dos censos escolares indicarem um salto no número de matrículas de alunos com deficiência no ensino regular, o desafio da educação superior para essa população ainda está longe de ser atingida, porque não são apenas os índices quantitativos que precisam ser alterados: TODOS precisam ter oportunidade de acesso a um ensino de qualidade.

Como se pode perceber, pelo estudo dos relatos, faltam políticas públicas em diversas áreas - educação, trabalho, saúde, transporte, lazer, esporte, moradia,...-, falta articular medidas específicas de atenção à diversidade e 
propostas de formação inicial e continuada aos professores para que respondam adequadamente aos princípios inclusivos.

Existem leis atuais e modernas a respeito da inclusão. Sabe-se que esses aparatos legais são importantes e necessários à educação para TODOS nos mais diversos níveis de ensino, mas o problema da sociedade atual está em efetivar a operacionalização dessas leis.

Desse modo, a fim de haver no país uma educação para TODOS, o governo precisa investir em materiais pedagógicos, qualificação de professores, infraestrutura adequada para ingresso, acesso e permanência e, nas diversas instituições de ensino, os dirigentes devem estar atentos a qualquer forma de atitude discriminatória. Para tanto, é fundamental a implementação de políticas educacionais que explicitem, em seus programas, de que forma as universidades públicas poderão buscar recursos financeiros para se equiparar adequadamente a essas necessidades.

Como lembram Marques e Marques (2003, p. 237), é função social da universidade "mostrar com clareza as contradições sociais e propor alternativas concretas, pois é nesse contexto que está a perspectiva de incluir".

Reafirma-se, a partir deste estudo, a necessidade de realização de outras pesquisas que acompanhem o processo de consolidação da proposta de acesso no Ensino Superior das pessoas com deficiência.

\section{Referências}

ALVES-MAZZOTI, A. J.; GEWANDSZNAZDER, F. O método nas ciências naturais e sociais. São Paulo: Pioneira, 1998.

BRASIL. Ministério da Educação. Secretaria de Educação Especial. Direito à educação: subsídios para a gestão dos sistemas educacionais - orientações gerais e marcos legais. Brasília: 2006.

BRASIL. Ministério da Educação. Plano de Desenvolvimento da Educação: razões, princípios e programas. Brasília: 2007.

BRASIL. Ministério da Educação. Secretaria Especial dos Direitos Humanos, Coordenadoria Nacional para Integração da Pessoa Portadora de Deficiência. Convenção sobre os Direitos das Pessoas com Deficiência. Brasília, 2007.

CARMO, A. A. do C. Aspectos históricos, filosóficos e sociológicos da deficiência. In: FERREIRA, E. L. (Org.). Atividade física para pessoas com deficiência física. Juiz de Fora: ED. UFJF, 2008.

CHAHIN, T. H. C. O desafio do acesso e permanência dos alunos com necessidades educacionais especiais nas IES de São Luis do Maranhão. 2006. 212 f. Dissertação (Mestrado em Educação) - Faculdade de Educação, Universidade Federal do Maranhão, São Luis, 2006. 
CHIZZOTTI, A. Pesquisa em Ciências Humanas e Sociais. São Paulo: Cortez, 1991.

DELPINO, M. Facilidades e dificuldades encontradas pelos alunos com deficiência visual no curso superior. 2004. 185 f. Dissertação (Mestrado em Distúrbios do Desenvolvimento), Universidade Presbiteriana Mackenzie, São Paulo, 2004.

DEMO, P. Avaliação qualitativa. São Paulo: Cortez, 1991.

DREZZA, E. J. Inclusão no Ensino Superior: relato de experiência sobre uma política de inclusão na Universidade Cidade de São Paulo. 2007. 75 f. Dissertação (Mestrado em Educação) - Universidade Cidade de São Paulo, São Paulo, 2007.

DUARTE, E. R. A inclusão de pessoas com deficiência nas instituições de ensino superior e nos cursos de educação física de Juiz de Fora pede passagem. E agora? 2009. 162 f. Dissertação (Mestrado em Educação Física) - Universidade Federal de Juiz de Fora, Juiz de Fora, Viçosa, 2009.

FERREIRA, M. E. C.; GUIMARÃES, M. Educação Inclusiva. Rio de Janeiro: DP\&A, 2003.

FERREIRA, S. L. Ingresso, permanência e competência: uma realidade possível para universitários com necessidades educacionais especiais. Revista Brasileira de Educação Especial, São Paulo, v. 13, n. 1, p. 43-60, jan. 2007.

GIL, A. C. Métodos e técnicas de pesquisa social. São Paulo: Atlas, 1995.

GOMES, M. de F. C.; LIMA, P. A. L. Inclusão e exclusão: a dupla face da modernidade. In: SEMINÁRIO INTERNACIONAL SOCIEDADE INCLUSIVA, 2006, Belo Horizonte. Anais... Belo Horizonte: [s. n.], 2006. p. 16.

INSTITUTO NACIONAL DE ESTUDOS E PESQUISAS EDUCACIONAIS ANÍSIO TEIXEIRA (BRASIL). Censo da Educação Superior Escolar, 2007. Disponível em: < http://www.inep.gov.br/ basica/censo/default.asp >. Acesso em: 20 jan. 2007.

LIMA, O. M. B. de. A trajetória de inclusão de uma aluna com NEE, Síndrome de Down, no Ensino Superior: um estudo de caso. 2007. 87 f. Dissertação (Mestrado Educação) - Faculdade de Educação, Pontifícia Universidade Católica do Rio Grande do Sul, Porto Alegre, 2007

MANSINI, E.; BAZON, F. A inclusão de estudantes com deficiência no Ensino Superior. São Paulo: Universidade Presbiteriana Mackenzie, 2006.

MARQUES, C. A.; MARQUES, L. P. Do universal ao múltiplo: os caminhos da inclusão. In: SOUSA, L. F. et al. Políticas educacionais, práticas escolares e alternativas de inclusão escolar. Rio de Janeiro: DP\&A, 2003. 
MAZZOTA, M. J. S. Educação especial no Brasil: história e políticas públicas. São Paulo, Cortez, 1996.

MOREIRA, L. C. In(ex)clusão na universidade: o aluno com necessidades educacionais especiais em questão. Revista Educação Especial, Santa Maria, n. 25, p. 37-47, ago. 2005.

OLIVEIRA, L. C. P. Trajetórias escolares de pessoas com deficiência visual: da educação básica ao Ensino Superior. 2007. 158 f. Dissertação (Mestrado Educação) - Faculdade de Educação, Pontifícia Universidade Católica de Campinas, Campinas, 2007.

PACHECO, R. V.; COSTAS, F. A. T. P. Processo de inclusão de acadêmicos com necessidades educacionais especiais na Universidade Federal de Santa Maria. Revista Educação Especial, Santa Maria, n. 27, p. 151-170, jul. 2006.

PELLEGRIN, C. M. Ingresso, acesso e permanência dos alunos com necessidades educacionais especiais na Universidade Federal de Santa Maria. 2006. 212 f. Dissertação (Mestrado em Educação) - Faculdade de Educação, Universidade Federal de Santa Maria, Santa Maria, 2006.

PERINI, T. Í. O processo de inclusão no Ensino Superior em Goiás: a visão dos excluídos. 2006. 121 f. Dissertação (Mestrado em Educação) - Faculdade de Educação Faculdade de Educação, Universidade Católica de Goiás, Goiânia, 2006.

PEREIRA, M. M. Inclusão e universidade: análise de trajetórias acadêmicas na Universidade Estadual do Rio Grande do Sul. 2007. 201 f. Dissertação (Mestrado Educação) - Faculdade de Educação, Universidade Federal do Rio Grande do Sul, Porto Alegre, 2007.

REGO, T. C. Memórias de escola: cultura escolar e constituição de singularidades. Petrópolis, RJ: Vozes, 2003.

RODRIGUES, D. A inclusão na universidade: limites e possibilidades da construção de uma universidade inclusiva. Cadernos de Educação Especial, Santa Maria, n. 23, 2004. Disponível em: <http:// www.ufsm.br/ce/revista/ceesp>. Acesso em: 13 ago. 2009.

SASSAKI, R. K. Inclusão: construindo uma sociedade para todos. Rio de Janeiro: WVA, 1997.

SAVIANI, D. O Plano de Desenvolvimento da Educação: análise do projeto do MEC. Educação e Sociedade, v. 28, n. 100, p. 1231-1255, 2007. Disponível em: <http://www.scielo.br/pdf/es/v28n100/a2728100.pdf>. Acesso em: 20 mar. 2009.

SEVERINO, A. J. Metodologia do trabalho científico. São Paulo: Cortez: Autores Associados, 1990. 
SILVA, E. L. da; MENEZES, E. M. Metodologia da pesquisa e elaboração de dissertação. Florianópolis: UFSC/PPGEP/LED, 2001.

VEROTTI, D. T.; CALLEGARI. A inclusão que ensina. In: Revista Nova Escola: Especial Inclusão. São Paulo: Abril S.A, jul. 2009.Edição Especial.

VYGOTSKY, L. S. A formaçâo social da mente. São Paulo: Martins Fontes, 1984.

Aprendizagem e desenvolvimento escolar. In: VYGOTSKY, L. S. et al. Linguagem, desenvolvimento e aprendizagem. São Paulo: Ícone/Edusp, 1988. p. $45-87$.

Notas

1 Programa Aprender a Ser - Projeto de Estudos Disponível em: <http://www.acegosjf.com.br/ ?pagina $=$ detalhes $\&$ tipo $=6 \&$ cat $=49>$. Acesso em: 10 maio 2009.

\section{Correspondência}

Emerson Rodrigues Duarte - Rua Padre Frederico, 180 Bairro Santa Catarina 36 036-150 Juiz de Fora, Minas Gerais, Brasil.

E-mail: duarte.emerson@terra.com.br

Recebido em 03 de junho de 2009

Aprovado em 18 de janeiro de 2010 